EPiC Series in Engineering
Volume 3, 2018, Pages 2233-2240
HIC 2018. 13th International
Conference on Hydroinformatics

\title{
Effects of climate change on streamflow in Kon - Ha Thanh river watershed, Vietnam
}

\author{
Ngoc Duong VO ${ }^{1,2}$, Quang Binh NGUYEN ${ }^{1}$, Huy Cong VU ${ }^{1}$, Philippe \\ GOURBESVILLE ${ }^{2}$, Thanh Hao NGUYEN ${ }^{1,2}$ \\ ${ }^{1}$ Faculty of Water Resource Engineering, \\ University of Science and Technology, the University of Da Nang, Viet Nam \\ ${ }^{2}$ Innovative City lab URE 005 \\ Polytech'Nice Sophia, Nice Sophia Antipolis University, France \\ vo.ngoc.duong@dut.udn.vn; ngbinh@dut.udn.vn; vhcongbk@gmail.com; \\ Philippe.GOURBESVILLE@unice.fr
}

\begin{abstract}
Climate change is a complex problem and becoming the leading challenge for humankind in the 21st century. It will affect almost aspects of human well-being. Therefore, assessing climate change impacts on water resources and proposed solutions to respond to climate change is urgent and necessary. This study applied the SWAT model (Soil and Water Assessment Tool) and GIS (Geographic Information System) technique to simulate water flows due to the impact of climate change. The models were applied for Kon - Ha Thanh river catchment, located in Vietnam where is considered as one of the countries most affected by climate change. The SWAT model is calibrated and validated well using daily flow data with the Nash-Sutcliffe and correlation coefficients are 0.77 and 0.88 , respectively. Two scenarios from Vietnamese government (RCP 4.5 and RCP 8.5) are used to analyze the variation of stream flow in three periods: 20162035, 2045-2065, and 2080-2100. The results show that the flow in Kon - Ha Thanh rivers will vary complicatedly and severely under the impact of climate change. This flow may increase roughly $150.8 \%$ in flood season and reduce around $11.8 \%$ in dry season. Furthermore, the study also demonstrates that there are the changes in the flood dynamics as well as the hydrological shift of this region. This study presents an operational approach to integrate the results from the impacts of climate change to flood protection measures that would be useful in sustainable planning and devising resilience strategies.
\end{abstract}

\section{Introduction}

Vietnam is considered as one of the countries to be severely affected by climate change (Change, 2001). Over 50 years, annual average temperature has increased by $0.5-0.70 \mathrm{C}$, and annual precipitation 
has decreased in the North and increased in the South, and the sea level has risen by $20 \mathrm{~cm}$ (MoNRE, 2009). In 2016, Vietnam suffered 10 typhoons and seven tropical depressions, more than the average of many years ago. Climate change is expected to continue to have a negative impact on production, life and environment, therefore response to climate change is of crucial importance to Vietnam. In areas affected by climate change, the changes in hydrologic cycle as well as the frequency of flooding are very diverse and complex. The hydrologic changes will affect almost aspects of human well-being, from agricultural productivity and energy use to flood control, municipal and industrial water supply (Kusangaya, Warburton, Van Garderen, \& Jewitt, 2014). Therefore, predicting the impact of climate change on catchment hydrology is a basic requirement for sustainable river basin management. In Vietnam, especially, the Kon - Ha Thanh rivers have been heavily affected by changing climate. These rivers sometimes experience very low-low flow conditions during dry season and flooding in rainy season as indicated by past record. Moreover, they are both prone to flash flooding due to intense storms and annual typhoons. Quy Nhon is downstream city of the Kon- Ha Thanh rivers and it is one of three representative cities of Vietnam that was chosen for the development of action plan to respond to climate change. The city is projected to be heavily affected by climate change, especially flood. This effect is even more severe in zone concentrated by low income people living in cultivated area, farmers and fishermen, leading to many socio-economic issues (Tran Thi, 2011). The assessment of climate change impacts as well as proposal of corresponding response measures is very important in the strategy development of this area.

The impact of climate change on river flow has been studied in numerical modelling in recent years. For predicting the long-term effect of hydrologic changes and watershed management practices, continuous simulation watershed model are useful. The Soil and Water Assessment Tool (SWAT) is widely used for long-term, continues simulation (Rahman, Bolisetti, \& Balachandar, 2010). Ashraf et al. (2011) used SWAT on the Mimbres river basin to simulate river discharge with different spatially distributed rainfall data (El - Sadek, Bleiweiss, Shukla, Guldan, \& Fernald, 2011). Raghavan et al. (2011) used the SWAT to predict stream flow (2071-2100) in Sesan catchment in Vietnam using the downscaled precipitation from Regional Climate Model, Weather Research Forecast driven by the global climate model ECHAM5 (Raghavan, Vu, \& Liong, 2012). Their findings proved that there is a marginal increase in stream flow in this region during flood season during at the end of the century. Easton et al. (2010) used SWAT to simulate runoff and erosion in the Blue Nile basin with source of runoff from Ethiopia (Easton et al., 2010). This paper presents a combined application of hydrological model SWAT with GIS technology to investigate the variation tendency of river flow under the impact of climate change. The climate scenarios are taken from Ministry of Natural Resource and Environment, Vietnam, 2016.

\section{Study area}

The Kon - Ha Thanh river watershed is one of the big river basins in in central region of Vietnam. It is The Kon River which has a basin area of $2582 \mathrm{~km} 2$ and a total river length of about $178 \mathrm{~km}$, and Ha Thanh river with a total river basin area of $549 \mathrm{~km} 2$ and a total river length of $38 \mathrm{~m}$ in South Central Vietnam and covers major parts of Binh Dinh Province, and a small part of Gia Lai Province. The topography is complex with the relatively narrow mountainous area on the upstream and the flat coastal zone at the downstream. The climate of this region follows the pattern of central highland in Asia with an annual average temperature of about 18-20 0C and total annual average rainfall of about 1800-3300 $\mathrm{mm}$ with $65 \%$ to $80 \%$ annual rainfall during the months from September to December. Spatial distribution of rainfall in study area is not uniform. The highland and the northern mountainous regions are the two areas with the highest rainfall with total average annual rainfall is from 2220 to $3030 \mathrm{~mm}$. 
The southwest monsoon season brings more rain to this region. This region is also suffered from two to four typhoons annually so the inundation is very serious.

\section{Methodology}

A semi distributed model (SWAT) is developed for representing the hydrological process of Kon $\mathrm{Ha}$ Thanh river catchment. The model is calibrated and validated relied on observed data of Binh Tuong station over eighteen years, from 1990 to 2008. Two scenarios (RCP4.5 and RCP8.5 released in 2016) from Viet Nam Government is used in this study to assess the impact of climate change on stream flow of Kon - Ha Thanh river over three periods 2016 - 2035, 2046 - 2065, 2080 - 2099.

\subsection{Data acquisition}

In this study, SWAT input requires spatial data like Digital Elevation Model (DEM), land use and soil map. The DEM were obtained with resolution 90×90m from Department of Survey and Mapping, Vietnam. Land use map was taken from the Forest Investigation and Planning Institute (FIPI) of Vietnam. In this area, mixed forest land use was the largest (42.47\%); follow by agricultural production (24.38\%); land for growing annual crops (16.87\%), land for construction of houses, industry, traffic roads, etc. $(15.82 \%)$ and water surface area $(0.46 \%)$. The Soil information was taken from Binh Dinh Province Department of Planning. Land types mainly distributed in the study area include: Loam Sand (41.62\%), Sand (23.12\%), Light Clay (18.77), Silt Loam (10.41\%) and Clay (6.08\%). The necessary precipitation data in daily format were obtained from 11 stations and temperature from 1 station. Time series of rainfall monitoring and temperature are 32 years from 1983 to 2014.
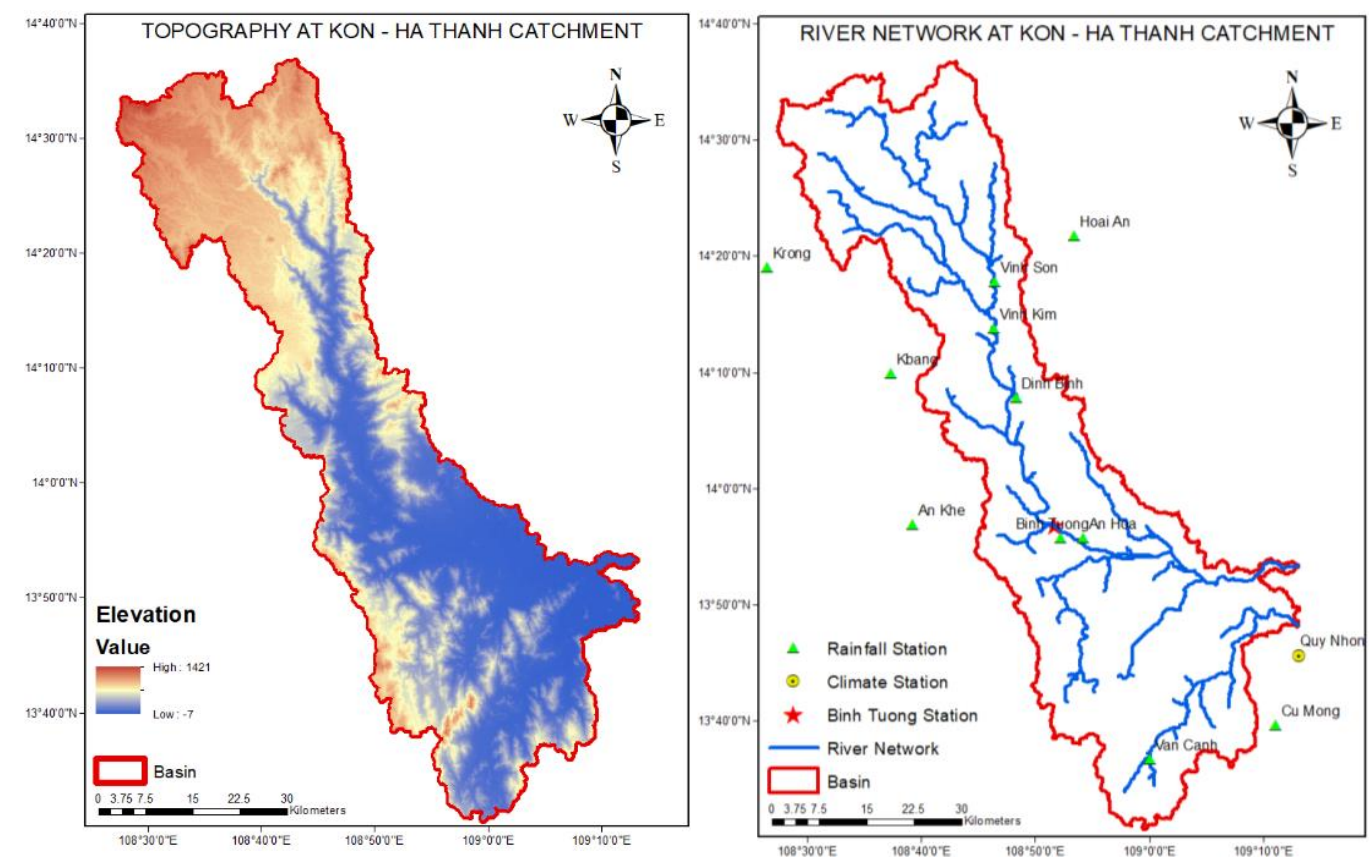

Figure 1 Bathymetry and river network at Kon - Ha Thanh catchment 

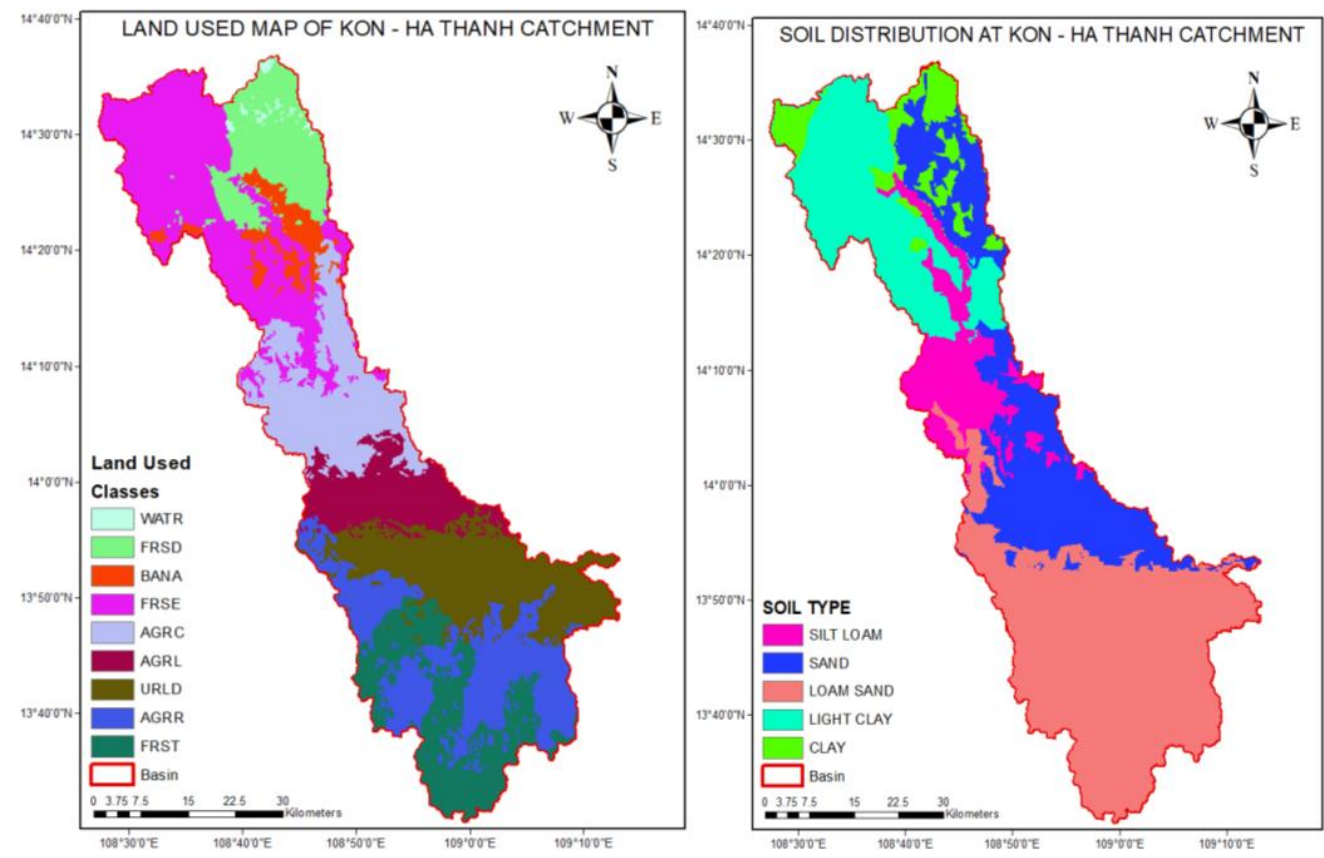

Figure 2 Land used map and soil distribution at Kon - Ha Thanh catchment

\subsection{SWAT calibration and validation}

The calibration and validation periods were chosen by considering the continuous stream flow data. A ten-year calibration period was chosen for SWAT from 1990 to 1999 the validation period was 9 years from 2000 to 2008. This process was conducted based on observed discharge data recorded at Binh Tuong station. Three commonly used model efficiency criteria were used to evaluate the performance of the model including the root mean squared error (RMSE), the correlation coefficient (R), Nash-Sutcliffe coefficient (E).

Due to the semi distributed characteristic of SWAT model, calibration is carried on three principal parameter groups which physically represent for overland flow, ground water flow and stream flow. The strategy of calibration fisrtly focuses on ground water flow by controlling two parameters: Groundwater delay (Gw_Delay), Baseflow alpha factor (Alpha_Bf). Afterward, SCS runoff curve number for moisture condition II (CN2), Manning's N value for overland flow (OV-N), Manning's n value for main channel (CH_N1, CH_N2), Effective hydraulic conductivity in the tributary channel alluvium (CH_K1), Effective hydraulic conductivity in the main channel alluvium (CH_K2), Surface runoff lag coefficient (SURLAG) are successively adjusted to conduct the peak flow and hydrograph shape.

\section{Results and discussion}

\subsection{Calibration and validation}

The simulated and observed stream flow plot for the calibration and validation performance is presented in Figure 3. It can be seen that model predicted flows are in good agreement with observed data. Importantly, the model is able to capture the peaks of discharge and this is useful to simulate flood 
events. Furthermore, 3 efficiency criteria presented in Table 1 make evidence for the model simulated quality. The $\mathrm{R}$ and $\mathrm{E}$ coefficients in the calibration and validation periods are 0.87, 0.76 and $0.88,0.77$, respectively indicating good model performance. The RMSE coefficients in both periods are relatively small $93.38 \mathrm{~m}^{3} / \mathrm{s}, 50.96 \mathrm{~m}^{3} / \mathrm{s}$, respectively. Take overall, the validation results indicate that the present model is suitable for investigating the variation of stream flow under effect of climate change.

\begin{tabular}{ccccccc}
\hline \multirow{2}{*}{ Station } & \multicolumn{3}{c}{ Calibration (1990-1999) } & \multicolumn{3}{c}{ Validation (2000-2008) } \\
\cline { 2 - 7 } & $\begin{array}{c}\text { RMS } \\
\left(\mathrm{m}^{3} / \mathrm{s}\right)\end{array}$ & $\mathrm{R}$ & $\mathrm{E}$ & $\begin{array}{r}\mathrm{RMS} \\
\mathrm{E}\left(\mathrm{m}^{3} / \mathrm{s}\right)\end{array}$ & $\mathrm{R}$ & $\mathrm{E}$ \\
\hline Binh Tuong & 93.38 & 0.87 & 0.76 & 50.96 & 0.88 & 0.77 \\
\hline
\end{tabular}

Table 1 Statistical indices of models in Kon - Ha Thanh catchment

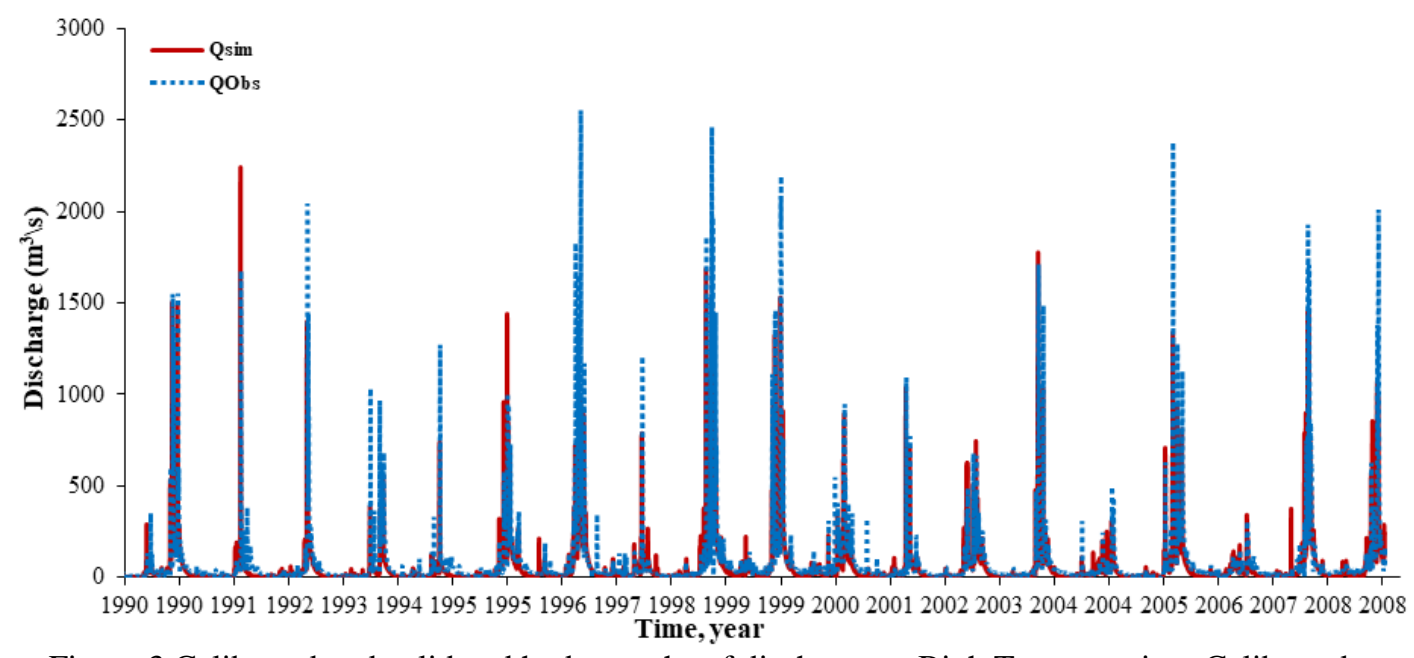

Figure 3 Calibrated and validated hydrographs of discharge at Binh Tuong station; Calibrated $(1990-1999)$, validated $(2000-2008)$

\subsection{Climate change}

\subsubsection{Change in flood flow}

The variation in annual cycle of flood flow in Kon - Ha Thanh river system is shown in Figure 4. It can be seen that the increase in flow during the rainy season are noticeable. This change might be explanted by the consequence of the higher increase of precipitation than evapotranspiration in rainfall season. For the period of 2046-2065, the largest flow is obtained in the rainy season (November), with values of $280.6 \mathrm{~m}^{3} / \mathrm{s}, 272.65 \mathrm{~m}^{3} / \mathrm{s}$ for RCP4.5, RCP 8.5 , respectively. However, in the dry season (May), this period have smallest flow compared to other periods. The flows for RCP4.5, RCP8.5 scenarios are $27.66 \mathrm{~m}^{3} / \mathrm{s}, 24.2 \mathrm{~m}^{3} / \mathrm{s}$, respectively. Generally, the monthly flow for all three periods of RCP4.5 tend to be higher than that of RCP8.5 

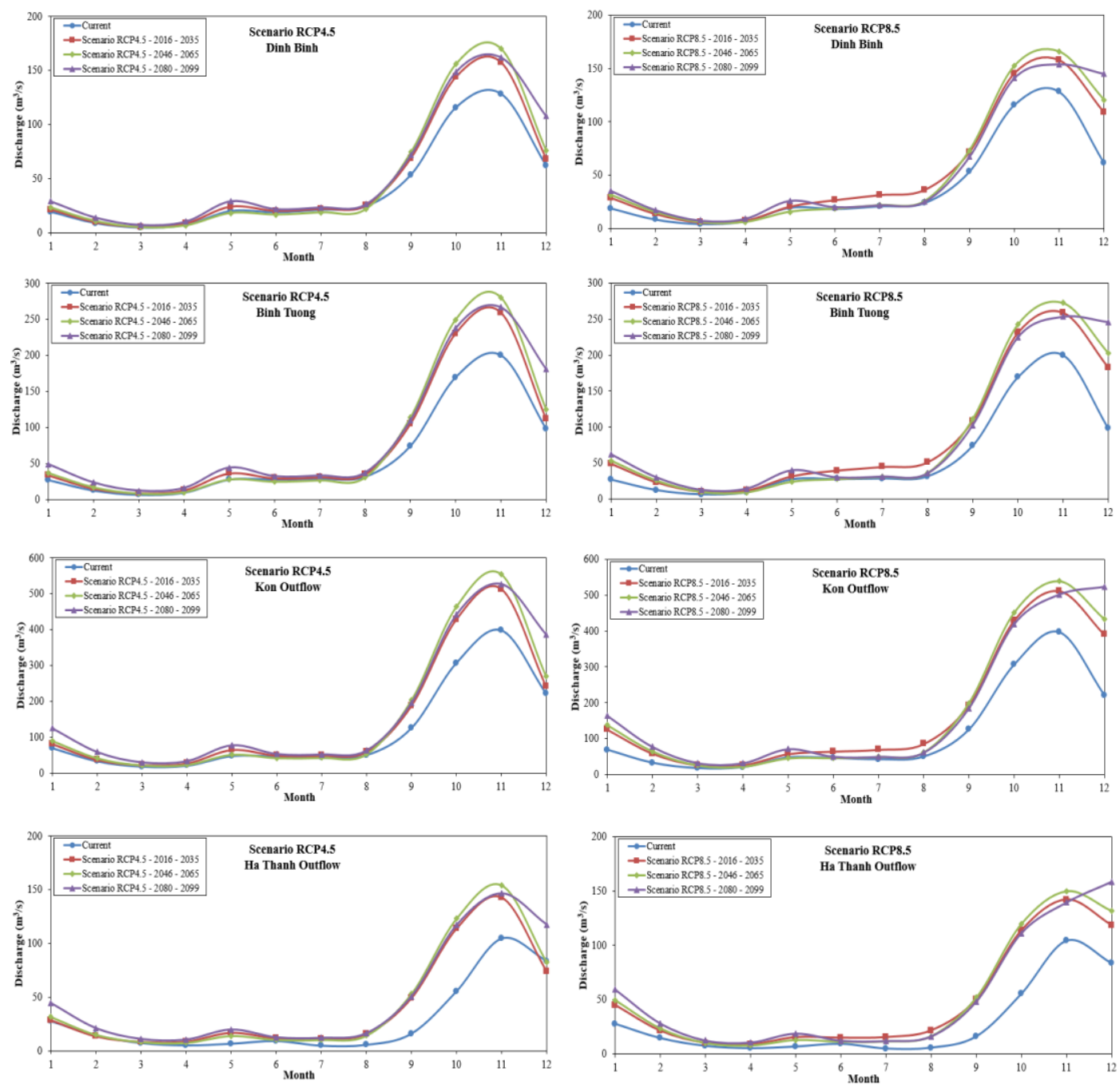

Figure 4 Baseline and future stream flows at Kon Ha Thanh catchment for Scenarios 4.5 and 8.5

\subsubsection{Change in low flow}

The drought situations occur complicatedly in this region. Especially, with the pressure of high speed in social economic development together with increase in population, the requirement of water in dry season becomes more and more urgent. Thus, it is necessary to estimate the runoff in dry season under the effect of climate change. This study shows that the low flow in Kon - Ha Thanh river system decrease due to the increase in temperature and in evapotranspiration (see Figure 4). It can be seen that the greatest water shortage will occur in the two periods 2016-2035 and 2080-2099 in the Kon- Ha Thanh rivers basin. Several areas of this catchment will face with significant drought risks. This poses a major challenge to the watershed managers in the planning and using of water resources. 


\subsubsection{Hydrological shift}

Figure 5 shows that the flood and dry seasons in the end of 21st century will come earlier than present. This earlier appearance tendency may have negative effects on agricultural production and economic activities in this region. Specifically, during the flood season of 2080-2099 period, there is the largest increase in the flow up to $150.8 \%$ in December (RCP8.5). Conversely, during the dry season, amount of water may fall to $11.8 \%$ in May (RCP8.5).
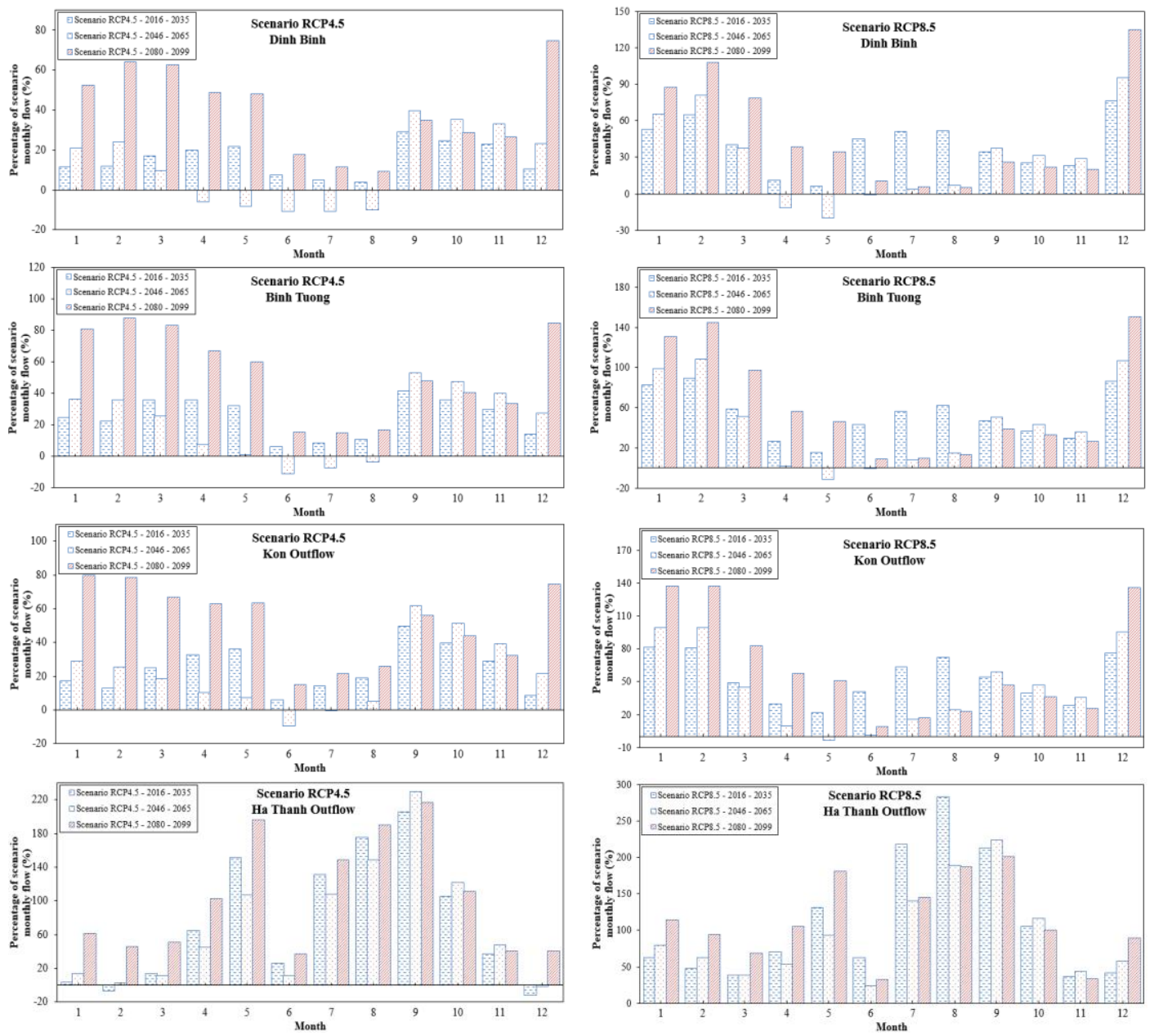

Figure 5 Percentages of future monthly stream flow in comparing with present for Scenarios 4.5 and 8.5

\section{Conclusion}

The variation trend of run off factors in Kon -Ha Thanh catchment under the impact of climate change was analysed using two scenarios (RCP 4.5 and RCP 8.5) with three periods: 2016-2035, 20462065, and 2080-2099. This study show that the flow in Kon - Ha Thanh river will vary complicatedly 
and severely in future. This flow may increase roughly $150.8 \%$ in flood season and reduce around $11.8 \%$ in dry season. Further more the flood and dry seasons in the end of 21 st century will come earlier than present.

\section{Acknowledgement}

This research is funded by Funds for Science and Technology Development of the University of Danang under grant number B2017-ĐN02-20.

\section{References}

Change, I. P. O. C. (2001). Climate change 2007: impacts, adaptation and vulnerability. Genebra, Suíça. Easton, Z. M., Fuka, D. R., White, E. D., Collick, A. S., Biruk Ashagre, B., McCartney, M., ... Steenhuis, T. S. (2010). A multi basin SWAT model analysis of runoff and sedimentation in the Blue Nile, Ethiopia. Hydrology and Earth System Sciences, 14(10), 1827-1841.

El- Sadek, A., Bleiweiss, M., Shukla, M., Guldan, S., \& Fernald, A. (2011). Alternative climate data sources for distributed hydrological modelling on a daily time step. Hydrological Processes, 25(10), 1542-1557.

Kusangaya, S., Warburton, M. L., Van Garderen, E. A., \& Jewitt, G. P. W. (2014). Impacts of climate change on water resources in southern Africa: A review. Physics and Chemistry of the Earth, Parts A/B/C, 67, 47-54.

MoNRE, C. C. (2009). Sea Level Rise Scenarios for Vietnam. Ministry of Natural Resources and Environment, Hanoi, Vietnam.

Raghavan, S. V, Vu, M. T., \& Liong, S. (2012). Assessment of future stream flow over the Sesan catchment of the Lower Mekong Basin in Vietnam. Hydrological Processes, 26(24), 3661-3668.

Rahman, M., Bolisetti, T., \& Balachandar, R. (2010). Effect of climate change on low-flow conditions in the Ruscom River watershed, Ontario. Transactions of the ASABE, 53(5), 1521-1532.

Tran Thi, V. (2011). Climate change impacts and adaptation measures for Quy Nhon city. 